\title{
Studies On Biodiesel Synthesis Using Nanosilica Immobilised Lipase In Inverse Fluidized Bed Bioreactors
}

\author{
C. M. Narayanan and Aditi Pandey \\ Department of Chemical Engineering, National Institute of Technology, Durgapur, India \\ cmn_recd@yahoo.co.in , www.profcmn.com
}

\begin{abstract}
Biodiesel synthesis from neem oil and methyl acetate using lipase catalyst immobilised in nanosilica particles in a continuous inverse fluidised bed bioreactor of modified design has been analysed. The process has been simulated mathematically by developing a multiparameter software package and subsequently verified through pilot plant tests(experiments).The improved performance characteristics of the bioreactor of proposed design have been highlighted. Graphical data have been presented to illustrate the dependence of reactor performance on system/operating parameters such as substrate flow rate, catalyst loading and molar ratio of oil to acetate in the blend(substrate solution). The downflow mode of operation is an added advantage of these bioreactors which tends to reduce their operating cost. Due to the use of nanoparticles, the effectiveness factor is close to unity and consequently, the global rate of transesterification is more or less equal to the intrinsic rate. This enhances the performance efficiency of the bioreactor.
\end{abstract}

Keywords: Nanosilica particles, immobilised lipase, inverse fluidized bed bioreactor, biodiesel synthesis, software development, dispersed flow.

\section{INTRODUCTION}

The importance of biodiesels as green fuels and as viable substitutes to petroleum oil need not have to be overemphasised. The process of trans-esterification of vegetable oils using a low molecular weight alcohol or alkyl acetate has also been well-investigated in the laboratory and kinetic equations have been developed ${ }^{1,2,3}$.Nevertheless, design and analysis of industrial bioreactors for biodiesel synthesis has been relatively less investigated.

The most recommended vegetable oils for biodiesel manufacture are jatropha oil, algal oil ${ }^{4.5}$, waste cooking oil ${ }^{6}$ and neem $\mathrm{oil}^{7,8}$. Jatropha grows as tall trees and demands large land requirement, whereas microalgae could be grown on wasteland and in waste ponds and the oil yield from algae per hectare of land is around 20 times that from jatropha plantations. Waste cooking oils are, no doubt, low cost materials, but are of uncertain composition (demand large scale pre-treatment) and are of restricted availability. Neem oil is an excellent proposition, but is yet to receive government subsidy in India as an industrial raw material.

Among the alcohols, methanol, ethanol and propanol are most popular. Higher alcohols tend to cause increase in viscosity of the biodeisel produced. The very purpose of trans-esterification is to reduce the viscosity of vegetable oil, while keeping its attractive fuel/combustion characteristics including engine performance intact. High viscosity of fuel oil, as is well known, increases the cost of atomisation significantly. Alkyl acetates (methyl, ethyl or propyl acetate) are reportedly better propositions when trans-esterification is being performed in presence of immobilised lipase enzyme as catalyst ${ }^{9}$. This is due to the fact that the glycerol formed (when alcohol is being used for trans-esterification) has a tendency to deactivate the immobilised lipase, while with alkyl acetate, the byproduct formed is glycerol triacetate and this is reportedly harmless and does not cause any adverse effect on lipase catalyst.

Among the catalysts, alkali(sodium alkoxide) and acid(dilute sulphuric acid) catalysts are homogeneous catalysts and they do help in attaining a high rate of trans-esterification. However, there could be formation of soap when sodium alkoxide is used as catalyst and this tends to contaminate the biodiesel produced and would then demand expensive downstream processing. Dilute sulphuric acid tends to form acid sludge and a separate sludge processing unit would be necessary for its treatment and utilisation (for the economical recovery and utilisation of its sulphur content).

The use of metallic oxides and silicates as heterogeneous catalysts for biodiesel synthesis has also been investigated in the laboratories. However, most studies, if not all, report the yield and characteristics of biodiesel produced and hardly any of them have reported development of any kinetic equation for the process. Examples are the studies reported by Feyzi and Norouzi ${ }^{10}$ who have investigated biodiesel production from waste sunflower oil and methanol using magnetic $\mathrm{Ca} / \mathrm{Fe}_{3} \mathrm{O}_{4} @ \mathrm{SiO}_{2}$ nanocatalysts ( the yield of biodiesel reported by them is $97 \%$ at $65 \mathrm{C}$ ) and those of $\mathrm{Hu}$ et.al ${ }^{11}$ who report $93.7 \%$ yield of biodiesel at $81.5 \mathrm{C}$ from rapeseed oil and methanol in presence of $\mathrm{KF} / \mathrm{CaO}$ catalyst. Kawashima et. $\mathrm{al}^{12}$. studied catalytic activities of thirteen different metallic oxides for trans-esterification of rapeseed oil with methanol at $60 \mathrm{C}$ and out of these, calcium - containing catalysts have been reported to give the highest yield of $90 \%$ biodiesel. In the same way, Long, Fang and Yang ${ }^{13}$ have demonstrated that calcined sodium silicate is an effective catalyst for the microwave-irradiated production of biodiesel from rapeseed oil and jatropha oil with methanol (yield $\approx 96 \%$ ).

Enzymes ( in the present case, lipase enzyme) are commonly used in the immobilised state and thus are heterogeneous catalysts. Though the rate of reaction shall be lower, the biodiesel obtained shall be uncontaminated. This minimises the cost of downstream processing and eliminates the installation and maintenance costs of the additional sludge treatment unit.

Lipase enzyme may be immobilised in silica granules, particles made of activated carbon or polymer composites. Nanosilica particles make a good choice as support particles for immobilising the enzyme since they process enormously large specific surface and thereby minimise (practically eliminate) the resistance to substrate transfer into the particle 
(solid phase). This resistance is characteristic of heterogeneous systems and this tends to bring down the global rate of reaction. The present project deals with computer aided design and analysis of biodiesel synthesis using nanosilicaimmobilised lipase.

With nanoparticles, the problem of catalyst handling comes into forefront. Conventional packed bed and fluidized bed (including semi-fluidized bed) bioreactors are ruled out. The only choice is an inverse fluidised bed (of modified design) or a circulating fluidised bed ${ }^{14,15}$. In the present study, we have considered biodiesel synthesis from neem oil and methyl acetate in inverse fluidised bed reactor that employs lipase immobilised nanosilica particles.

\section{MATHEMATICAL MODELLING AND SOFTWARE DEVELOPMENT}

Conventional inverse fluidised bed bioreactors ${ }^{16,17}$ employ solid particles that are lighter than the feed solution so that they remain suspended (fluidised) in the descending stream of fluid. However, in the present case, nanosilica particles are much heavier than the feed solution (composed of neem oil and methyl acetate) and consequently, a bioreactor of modified design is to be employed. This design is sketched schematically in figure (1) and is similar to that proposed by Narayanan and co-workers ${ }^{15}$.

As shown in figure (1), the raw materials such as neem oil and methyl acetate are first blended in a selected molar proportion $(y)$ in the blending tank and then mixed with nanosilica particles containing immobilised lipase in the mixing tank at a specified mass ratio $\left(C_{L}\right)$ and thereafter fed to the bioreactor column from the top. This fine suspension flows down the vertical column (the bioreactor may be composed of multiple tubes/columns so as to increase the capacity of the reactor) and as it descends, the substrate solution diffuses into the nanoparticles where it meets the lipase catalyst and transesterification occurs. The product solution ( biodiesel, glycerol triacetate) in which the nanosilica particles are suspended leaves the bottom of the column and is sent to a nano-membrane filter to separate the nanoparticles. The permeate (product solution) is sent to storage and the nanoparticles are conveyed back to the overhead mixing tank pneumatically using compressed air (through the vertical pneumatic column).

Since the suspension is composed of nanoparticles and the ratio of solid particles to substrate solution is not maintained very large, it shall not be wrong to assume that the fine suspension is equivalent to a Newtonian liquid of density, $\rho_{L m}$ and viscosity , $\mu_{L m}$. The bulk density $\rho_{L m}$ of the suspension is defined as

$$
\rho_{\text {Lm }}=\rho_{L}\left(1+C_{L}\right)
$$

where

$$
\begin{aligned}
C_{L}= & \text { catalyst loading }, \mathrm{kg} / \mathrm{kg} \\
= & (\mathrm{kg} \text { of nanoparticles }) /(\mathrm{kg} \text { of oil-acetate blend }) \\
& \rho_{L}=\text { density of substrate solution (oil-acetate blend) }
\end{aligned}
$$

Since the substrate solution is a blend of neem oil and methyl acetate, its density $\left(\rho_{\mathcal{L}}\right)$ shall depend on the molar ratio of oil to acetate in the feed solution $(y)$. Thus,

$$
p_{L}=C_{S 0}\left[M_{A}+M_{B} l y\right]
$$

where $\quad C_{S 0}=$ molar concentration of neem oil in the feed solution (substrate solution).

$$
=1 /\left[\left(M_{A} / \rho_{A}\right)+M_{B} /\left(\gamma \rho_{B}\right)\right]
$$

$M_{A x} M_{B}=$ molecular weight of neem oil $(\mathrm{A})$ and that of methyl acetate (B) respectively, $\mathrm{kg} / \mathrm{kmole}$.

$\rho_{A_{1}} \rho_{B}=$ density of neem oil and that of methyl acetate respectively 


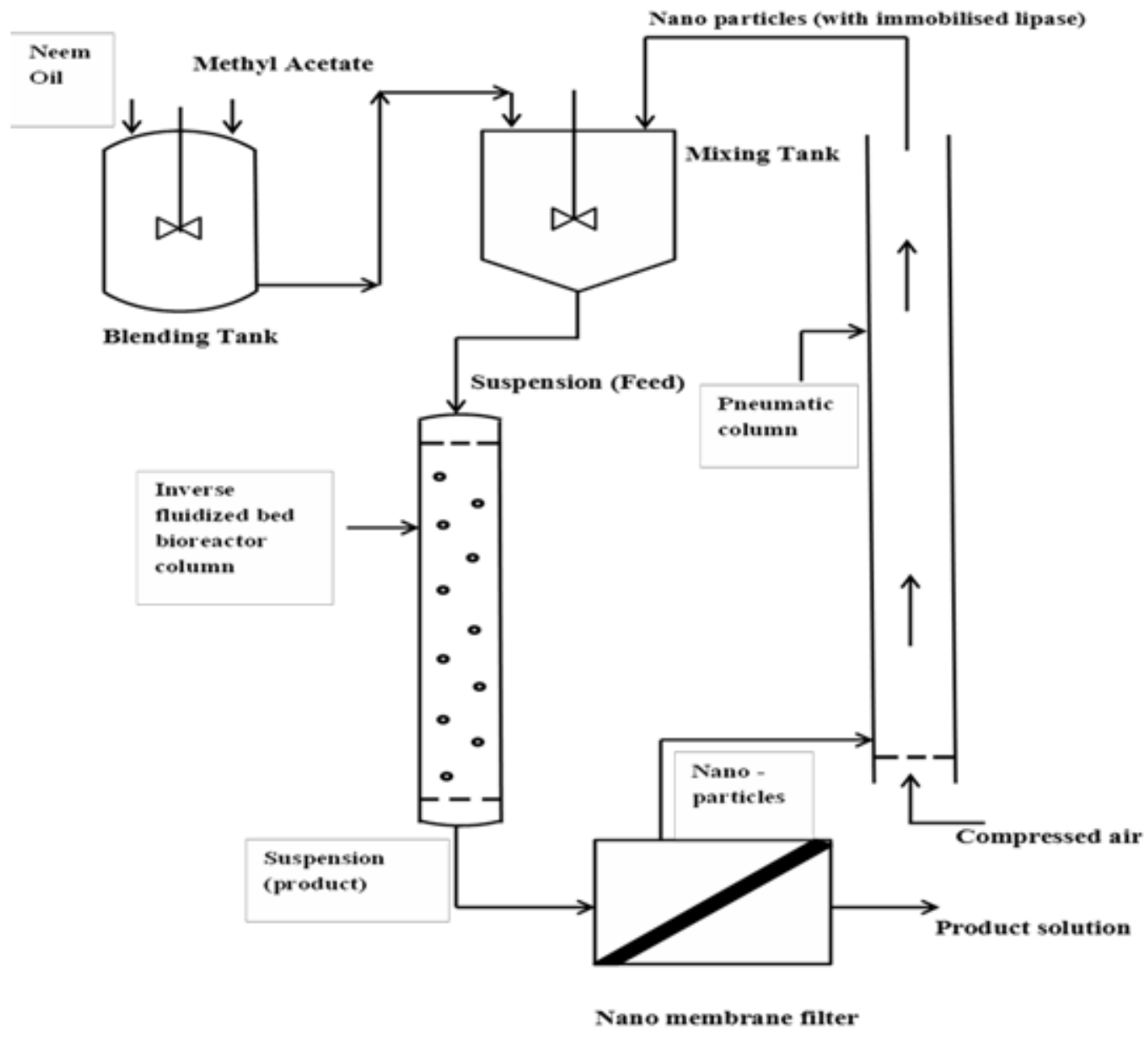

Figure - 1 : Schematic of Inverse Fluidized Bed Bioreactor of proposed design

The viscosity of the suspension $\left(\mu_{L m}\right)$ is taken equal to that of substrate solution $\left(\mu_{L}\right)$. Once again, the viscosity of the blend $\left(\mu_{L}\right)$ shall depend on the molar ratio of oil to acetate $(y)$ and the viscosity blending number of each component. Thus,

$$
\begin{aligned}
& \mu_{L}=\rho_{L}[\exp (X)-0.8]\left(10^{-6}\right) \\
& \text { where } \quad X=\exp [0.0688(\text { VBN })-0.755] \\
& V B N=\text { viscosity blending number of the substrate solution } \\
& =x_{A}(V B N)_{A}+\left(1-x_{A}\right)(V B N)_{B} \\
& x_{A}=\text { mass fraction of neem oil in the blend } \\
& =\left(y M_{A}\right) /\left(y M_{A}+M_{B}\right) \\
& (V B N)_{A}=\text { viscosity blending number of neem oil (A) } \\
& =(14.534) \ln \left[\ln \gamma_{A}+0.8\right]+10.975 \\
& =(14.534) \ln \left[\ln \gamma_{B}+0.8\right]+10.975
\end{aligned}
$$
bioreactor ( based on mass balance ) becomes 


$$
-U_{L}\left(d C_{S} / d z\right)+D_{L}\left(d^{2} C_{S} / d z^{2}\right)=\eta\left(-r_{S}\right)(i n t)
$$

where

$D_{L}=$ axial dispersion coefficient

$$
\eta \text { = effectiveness factor }
$$

$\left(-r_{S}\right)($ int $)=$ intrinsic rate of trans-esterification

$U_{L} \quad=$ average velocity of suspension through the reactor column

$$
=U(\sup ) / \epsilon_{\mathbb{L}}
$$

$U(\sup )=$ superficial velocity of substrate solution (oil-acetate blend) through the reactor column

$$
=Q_{0} /\left(\pi D^{2} / 4\right)
$$

$Q_{0}=$ volumetric flow rate of substrate solution $\left(\mathrm{m}^{3} / \mathrm{s}\right)$

$$
D=\text { diameter of reactor column }
$$

$E_{L}=$ volume fraction of liquid in suspension

$$
=1 /\left[1+\left(C_{L} \rho_{L} / \rho_{S}\right)\right]
$$

$\rho_{S}=$ density of nanosilica particles

The effectiveness factor $(\eta)$, which takes care of the resistance to substrate transfer into the particle, is a non-linear function of particle size, the effective diffusivity of substrate solution into the particle $\left(D_{\varepsilon}\right)$ and the kinetic constants associated with the intrinsic kinetics of trans-esterification. In the present case however, by virtue of the very small size of the nanoparticles, it has been observed that the effectiveness factor $(\eta)$ is equal to unity at all feed concentrations (at all values of $C_{50}$ ), irrespective of the type of kinetic equation and the numerical values of kinetic constants (computation procedure of $\eta$ is outlined in Appendix - A). Thus, for the present system,

(global rate of trans-esterification) $=$ (intrinsic rate of trans-esterification)

This happens to be one of the exclusive advantages of employing nanosilica particles for immobilisation of lipase. Equation (10), therefore, gets reduced to

$$
-U_{L}\left(d C_{S} / d z\right)+D_{L}\left(d^{2} C_{S} / d z^{2}\right)=\left(-r_{S}\right)(\text { int })
$$

The boundary conditions governing the system are

$$
\begin{aligned}
& \text { BC-1: At } \quad z=0 \quad \text { (top of the column), } C_{S}=C_{S O} \\
& \text { BC-2: At } \quad z=L \text { (bottom of the column), } C_{S}=C_{S e}
\end{aligned}
$$

If $\alpha$ is the fractional conversion of neem oil desired (the degree of trans-esterification desired), then

$$
C_{\text {Se }}=C_{\text {So }}(1-\alpha)
$$

From the above discussion, it is clear that the system/operating parameters affecting the performance of the bioreactor of proposed design are,

(a) Molar ratio $(y)$ of oil to acetate in the blend,

(b) Catalyst loading $\left(C_{\Sigma}\right)$,

(c) Volume flow rate of substrate solution $\left(Q_{0}\right)$,

(d) Dimensions of reactor column $\left(D_{x} L\right)$

The axial dispersion coefficient $\left(D_{L}\right)$, the magnitude of which decides the degree of axial dispersion occurring in the reactor column, is evaluated from the experimental correlation proposed by Levenspiel ${ }^{18}$. This correlation has been developed for Newtonian flow through straight, cylindrical columns/tubes. However, as stated earlier, since the fine suspension of nanosilica particles in the substrate solution (oil-acetate blend) has been assumed equivalent to a Newtonian fluid of density $P_{L m}$ and $\mu_{L m}$, the above correlation has been employed in a modified form for computing $D_{L}$ in the present study.

The intrinsic kinetics of lipase catalysed trans-esterification of neem oil by methyl acetate is described by the following correlation :

$$
\begin{aligned}
& \quad\left(-r_{S}\right)(\text { int })=\left[r_{\max }(\text { app }) C_{S} C_{S B}\right] /\left[K_{S 1} C_{S}+K_{S 2} C_{S B}+C_{S} C_{S B}\right] \\
& \text { where } \quad r_{\max }(a p p)=r_{\max }\left(C_{L} \rho_{L}\right)
\end{aligned}
$$

$\mathbf{6 0 7 5} \mid \mathrm{P}$ a g e 


$$
\begin{aligned}
C_{S B}= & \text { molar concentration of methyl acetate } \\
& =\left(b+3 C_{S}\right) \text { from stoichiometry } \\
b & =\left(C_{B O}-3 C_{S O}\right) \\
& =C_{S O}(1-3 y) / y \\
K_{S 2}= & K_{2}\left(1+C_{S B} / K_{S i}\right) \\
K_{S i}= & \text { substrate inhibition coefficient }
\end{aligned}
$$

The experimental values of kinetic constants ${ }^{8,19}$ are given below :

$$
\begin{gathered}
r_{\max }=4.78 \times 10^{-5} \mathrm{~mol} /(\mathrm{g} . \mathrm{s}) \\
K_{\text {S1 }}=15.837 \mathrm{~mol} / \mathrm{L} \\
K_{2}=1.12 \mathrm{~mol} / \mathrm{L} \\
K_{\text {Si }}=0.053 \mathrm{~mol} / \mathrm{L}
\end{gathered}
$$

The above kinetic equation has been experimentally verified and it predicts that at high concentrations, methyl acetate tends to inhibit the enzyme activity.

As stated earlier, the effectiveness factor $(\eta)$ that predicts the resistance to the transfer of substrate solution into the particle ( solid phase), is a non - linear function of the characteristic dimension of the particles $\left(L^{*}\right)$, the effective diffusivity $\left(D_{e}\right)$ of the substrate solution into the particle and the kinetic constants. When the intrinsic kinetics of the process is too non-linear as is in the present case, $\eta$ is computed from the generalised correlation given below :

$$
\eta=[3 \phi \operatorname{coth}(3 \phi)-1] /\left(3 \phi^{2}\right)
$$

where

$$
\begin{aligned}
\phi & =\text { Thiele }- \text { type modulus } \\
& =L^{*}\left(-r_{S}\right)(\text { int }) /\left(2 D_{e} I\right)^{1 / 2} \\
I & =\int_{0}^{C_{S}}\left(-r_{S}\right)(\text { int }) d C_{S} \\
L^{*} & =\left(V_{P} / S_{p}\right)=\left(d_{p} / 6\right)
\end{aligned}
$$

$V_{p v} S_{F}=$ volume and surface area respectively of each particle

The integral of equation (29) is evaluated numerically ( by using Simpson's rule), after substituting the expression for intrinsic rate from equation (19). Also discussed earlier, for the bioreactor under consideration, the global rate of transesterification is high and is equal to the intrinsic rate itself (as $\eta=1.0$ ).

The performance equation of the bioreactor (equation-15) is solved numerically based on the prescribed boundary conditions (equations-16, 17) using the numerical algorithm, NUMCM which is based on a modified form of fourth order Runge-Kutta method. This algorithm has been used by the author and his co-workers for the solution of non-linear, partial differential equations during many of their earlier investigations and the algorithm has been found to be quite stable and reasonably fast converging. The overall computational procedure may be summarized as given below:

1. A value of $y$ (molar ratio of neem oil to methyl acetate) is selected. For example, $y=1 / 3=$ stoichiometric proportion of neem oil to methyl acetate. The feed solution (substrate solution) thus becomes a blend that is composed of one part of neem oil and three parts of methyl acetate (by mole).

2. The concentration of neem oil in the feed solution $\left(C_{S O}\right)$ and the density $\left(\rho_{L}\right)$ and viscosity $\left(\mu_{L}\right)$ of the substrate solution are computed from equation (3), equation (2) and equations (4) to (9) respectively.

3. The catalyst loading $\left(C_{L}\right)$ is now chosen. In the present study, the values of $C_{L}$ considered are 0.1 to 0.7 . The bulk density of the feed slurry $\left(\rho_{\mathrm{Lm}}\right)$ is then determined from equation(1).

4. The volumetric flow rate of substrate solution (oil-acetate blend), $Q_{0}$, is selected. The average velocity of flow of feed slurry through the reactor column $\left(U_{L}\right)$ is then estimated from equations (11) to (13).

5. Equation (15) is now solved numerically using the algorithm, NUMCM. Computations are started from the bottom of the column where $z=0$ and $C_{S}=C_{S g}$ (this is thus the modified form of BC-2 given in equation-17):

a) The value of $\alpha$ (degree of transesterification of neem oil desired) is first selected and $C_{5 \mathbb{E}}$ is computed from equation (18).

b) Computations are continued upward with a step size $(\Delta z)$ of $1 \mathrm{~mm}$, until $z=L$. The value of $C_{S}$ at this value of $z$ is noted as $C_{\text {so }}(\mathrm{cal})$. 
c) It is checked whether $C_{50}$ (cal) is equal to (or slightly greater than) the value of $C_{50}$ specified in step-2. If not, computations are repeated from $\operatorname{step}(\mathrm{a})$, with an alternate value $\alpha$.

d) The value of $\alpha$ attained at the selected values of substrate solution flow rate $\left(Q_{0}\right)$, catalyst loading $\left(C_{L}\right)$ and substrate composition $(y)$ is thus computed by trial.

The algorithm has been re-executed at four different values of $y(y=1 / 3,1 / 5,1 / 7$ and 1/9) and at different valuesof catalyst loading $\left(C_{L}=0.1\right.$ to 0.7$)$ and in each case, at different values of substrate flow rate $\left(Q_{0}\right)$. The results are discussed and analysed in the subsequent section on Results and Discussion.

\section{EXPERIMENTAL STUDY (METHODS AND MATERIALS)}

Pilot plant tests (experiments) have been performed on a typical inverse fluidized bed bioreactor (sketched in figure - 1 ) with following specifications:

Column diameter $=25.4 \mathrm{~mm}$

No. of columns $=04$

Height of each column $=6.0 \mathrm{~m}$

Molar ratio of neem oil to methyl acetate $=1: 3,1: 7$

Catalyst loading $=0.1,0.4,0.7$

Flow rate of substrate solution $=2100$ to $2400 \mathrm{~L} / \mathrm{h}\left(0.000583\right.$ to $\left.0.000666 \mathrm{~m}^{\mathrm{a}} / \mathrm{s}\right)$

High purity neem oil and lab grade methyl acetate were procured from Arora Matthey Limited, Kolkata, India. Immobilised lipase particles (25 nm nanoparticles accommodating lipase enzyme) were supplied by Sigma Aldrich (P) Limited, Bangalore, India. Neem oil and methyl acetate were blended in the selected volumetric proportion in the overhead tank ( made of stainless steel) along with calculated amount of nanoparticles carrying the immobilized enzyme. The resulting suspension is fed to the top of the bioreactor and it is made to flow down the reactor columns / tubes as a continuous, descending stream. The substrate (suspension) flow rate per column ranged from $525 L / h$ to 600 $L / h\left(0.0001458\right.$ to $\left.0.000166 \mathrm{~m}^{\mathrm{a}} / \mathrm{s}\right)$. The flow rate was recorded using a flow transducer equipped with digital display. Nano-membrane made of treated polyamide composite was used to separate the nanoparticles. The separated nanoparticles are recycled back to the overhead mixing tank through the pneumatic column of $38 \mathrm{~mm}$ in diameter. The composition of feed solution (neem oil content) and that of product solution were recorded using a spectrophotometer (at 800 nm wave length) and a HPLC (High Pressure Liquid Chromatograph, Agilent Technologies 1200 Series, CA, USA). All test runs were repeated at least thrice to ascertain experimental accuracy.

By comparing all the experimental data compiled against the result obtained from the execution of the developed software package (simulation model), it is observed that the maximum deviation between $\alpha$ (experimental) and $\alpha$ (computed) is $\pm 11.5 \%$ and the minimum deviation is $\pm 6.5 \%$. The accuracy of the simulation model is thus ascertained.

\section{RESULTS AND DISCUSSION}

Once the software package(simulation model) has been tested and verified through elaborate pilot plant experiments, the discussion that follows is based on the results obtained by the re-execution of the simulation package at different values of Q $x y$ and $C_{L}$.

The variation of degree of transesterification of neem oil $(\alpha)$ with substrate flow rate $\left(Q_{0}\right)$ at different values of catalyst loading $\left(C_{L}\right)$ is illustrated graphically in figures (2) to (5). Each set of plots is for a specific value of $y$ (molar ratio of oil to acetate in the blend). From the family of plots presented in these graphical illustrations, the following inferences can be deduced:

1) As the molar ratio of neem oil to methyl acetate $(y)$ decreases (as the methyl acetate content of the substrate solution increases and the neem oil content relatively decreases), the fractional transesterification of neem oil attained $(\alpha)$ decreases. For example, when neem oil and methyl acetate are used in stoichiometric proportion $(y=1 / 3$ or 0.33$)$ and when the catalyst loading is maintained at 0.7 , the degree of transesterification attained is 0.88 (or $88 \%$ ) at a substrate flow rate $\left(Q_{0}\right)$ of $360 \mathrm{~L} / \mathrm{h}\left(0.0001 \mathrm{~m}^{3} / \mathrm{s}\right)$ and $\alpha=0.81$ at $Q_{0}=648 \mathrm{~L} / \mathrm{h}$ or 0.00018 $\mathrm{m}^{3} / \mathrm{s}$ (figure-2a). In comparison, when $y=1 / 5$ or 0.20 , the value of $\alpha$ (attained) is only $74 \%$ when the substrate flow rate is $360 \mathrm{~L} / \mathrm{h}\left(0.0001 \mathrm{~m}^{3} / \mathrm{s}\right)$ and $C_{L}=0.7$ and it is as low as $65 \%$ at higher flow rate $\left(Q_{0}=648 \mathrm{~L} / \mathrm{h}\right.$ or $0.00018 \mathrm{~m}^{3} / \mathrm{s}$ ) as illustrated in figure(3a). The degree of transesterifucation of neem oil falls deeply to $66 \%$ at $Q_{0}=360 \mathrm{~L} / \mathrm{h}\left(0.0001 \mathrm{~m}^{3} / \mathrm{s}\right)$ when the molar ratio is further decreased to (1/9) or 0.111 (figure-5a). This brings to the conclusion that among the two substrates (neem oil and methyl acetate), the neem oil concentration in the feed solution $\left(C_{50}\right)$ decides the degree of trans-esterification attained in the bioreactor. To note that as the molar ratio $y$ decreases, the molar concentration of neem oil $\left(C_{50}\right)$ decreases (equation-3). A high value of $C_{\text {So }}$ (a high 
value of $y$ such as 0.33 ) indicates larger degree of trans-esterification and larger yield of bio diesel. In other words, a large excess of methyl acetate (above the stoichiometric amount) is not advantageous and it only tends to decrease the biodiesel yield. This observation is in consonance with that reported by Tripti, Sikder and Narayanan ${ }^{8}$. This inference is also substantiated by the intrinsic kinetics of the process represented through equations (19) to (25), which, as stated earlier, predict that at large concentrations, methyl acetate causes inhibition to enzyme activity.

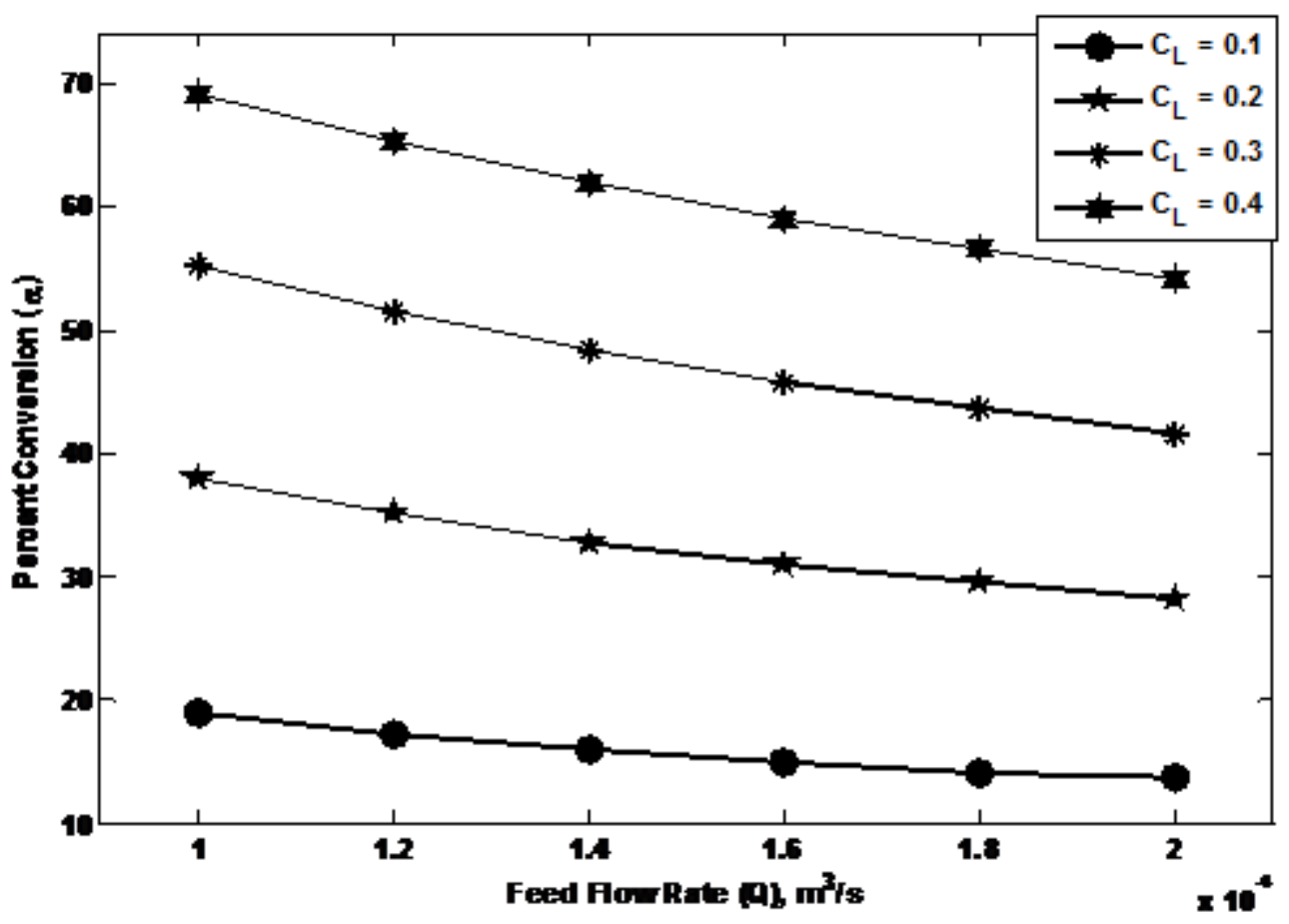

Fig 2: Variation of percent conversion with feed flow rate at different values of catalyst loading. $y=1 / 3, L=6.0 \mathrm{~m}, \mathrm{D}=25.4 \mathrm{~mm}$, single flow channel

2) The second interesting observation is that as the catalyst loading $\left(C_{L}\right)$ is increased, the degree of transesterification of neem oil $(\alpha)$ attained also increases at all substrate flow rates and at all values of molar ratio of oil to acetate $(y)$. For example, when $y=0.33$ or $1 / 3$ and $Q_{0}=360 \mathrm{~L} / \mathrm{h}\left(0.0001 \mathrm{~m}^{3} / \mathrm{s}\right)$, the value of $\alpha$ (attained) increases from $20 \%$ to $69 \%$ when the catalyst loading $\left(C_{L}\right)$ is increased from 0.1 to 0.4 (figure-2). Similarly, at $y=1 / 7$ (figure-4), the fractional conversion of neem oil increase from $13 \%$ to $43 \%$ when $C_{L}$ is increased from 0.1 to 0.4 at $Q_{0}=648 \mathrm{~L} / \mathrm{h}\left(0.00018 \mathrm{~m}^{3} / \mathrm{s}\right)$. A further increase to $60 \%$ is obtained at $C_{L}=0.7$. However, since a substrate conversion of more than $80 \%$ is obtained at $C_{L}=0.7$ within a range of substrate flow rates of 360 to $720 \mathrm{~L} / \mathrm{h}$ (in a single column reactor) at $y=0.33$, catalyst loadings higher than 0.7 shall be wasteful. The more or less optimum values of catalyst loading and molar ratio of oil to acetate shall be thus 0.7 and 0.33 (or $1 / 3$ ) respectively. 


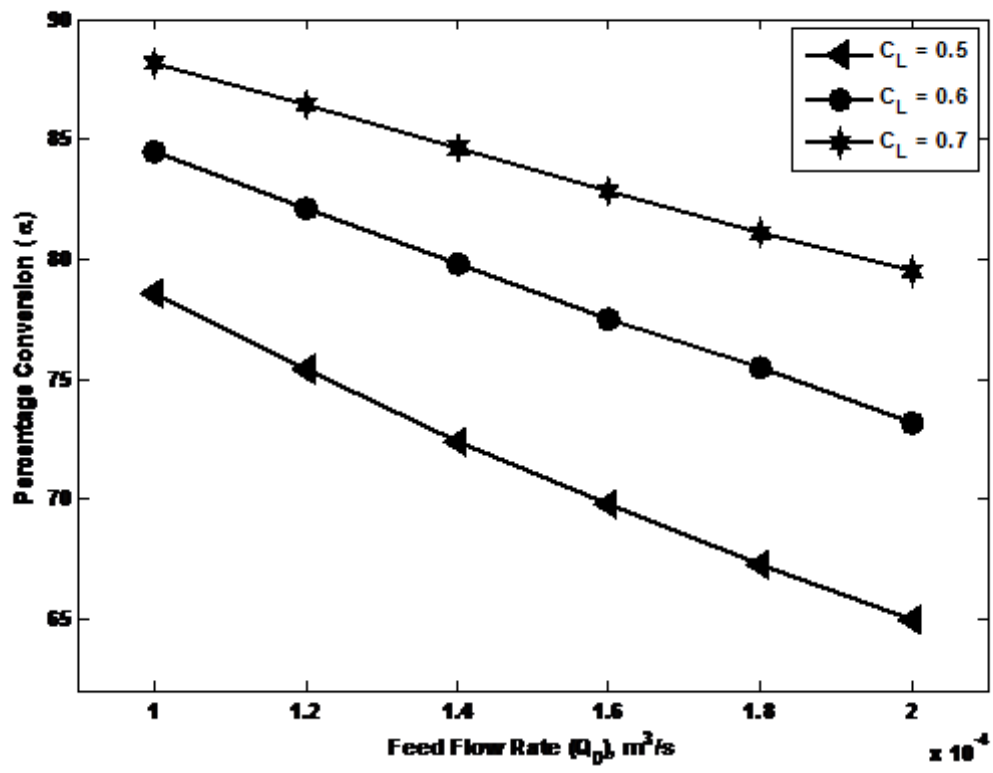

Fig 2a: Variation of percent conversion with feed flow rate at higher values of catalyst loading. $y=1 / 3, L=6.0 \mathrm{~m}, \mathrm{D}=\mathbf{2 5 . 4} \mathrm{mm}$, single flow channel

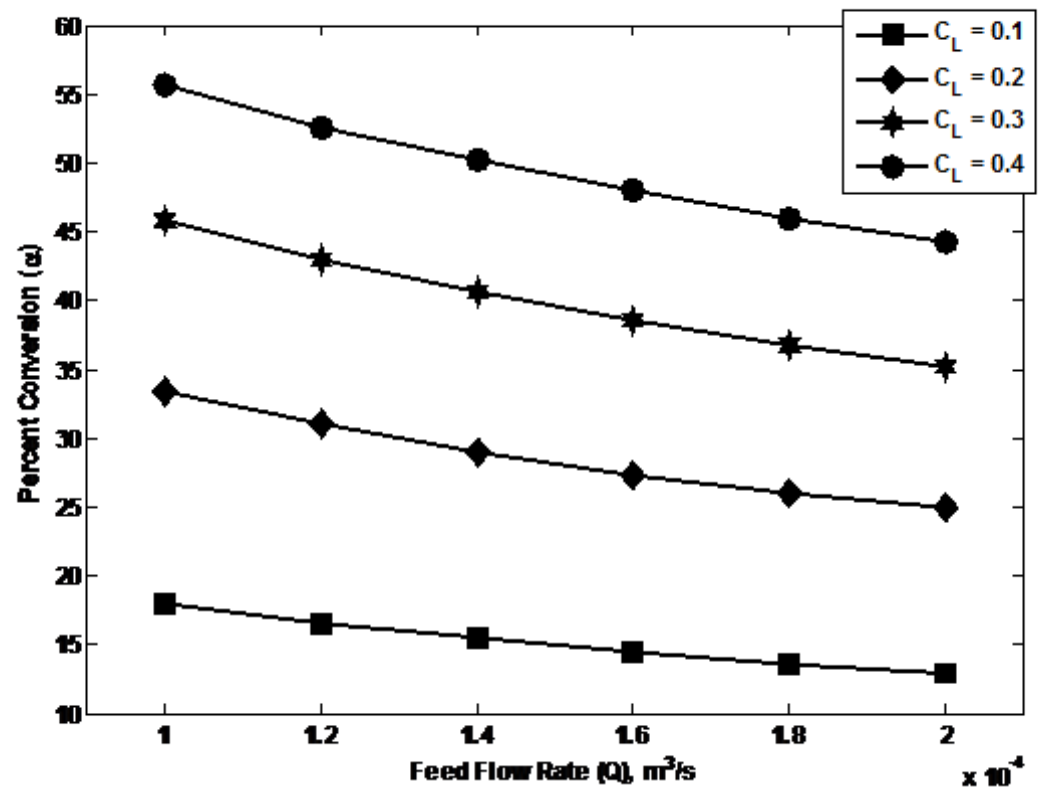

Fig 3: Variation of percent conversion with feed flow rate at different values of catalyst loading. $y=1 / 5, L=6.0 \mathrm{~m}, \mathrm{D}=\mathbf{2 5 . 4} \mathrm{mm}$, single flow channel

3) The degree of trans-esterification attained decreases with increase in substrate flow rate $\left(Q_{0}\right)$, though not very substantially, at all values of $y$ and at all values of $C_{L}$. This is understandable since as the feed flow rate is increased, the average residence time of feed slurry (fluid elements) in the bioreactor shall decrease and this would bring down the substrate conversion attained.

4) The bioreactor provides reasonably high degree of substrate conversion at reasonably high capacities within a reasonably low reactor volume. It may be noted that the data presented in figures(2) to (5) are for a single column reactor. If the bioreactor is composed of multiple columns/tubes (for example, 5 vertical columns/tubes, 
which is quite usual), then the reactor capacity shall increase to 1800 to $3600 \mathrm{~L} / \mathrm{h}$ (from the present capacity of 360 to $720 \mathrm{~L} / \mathrm{h})$.

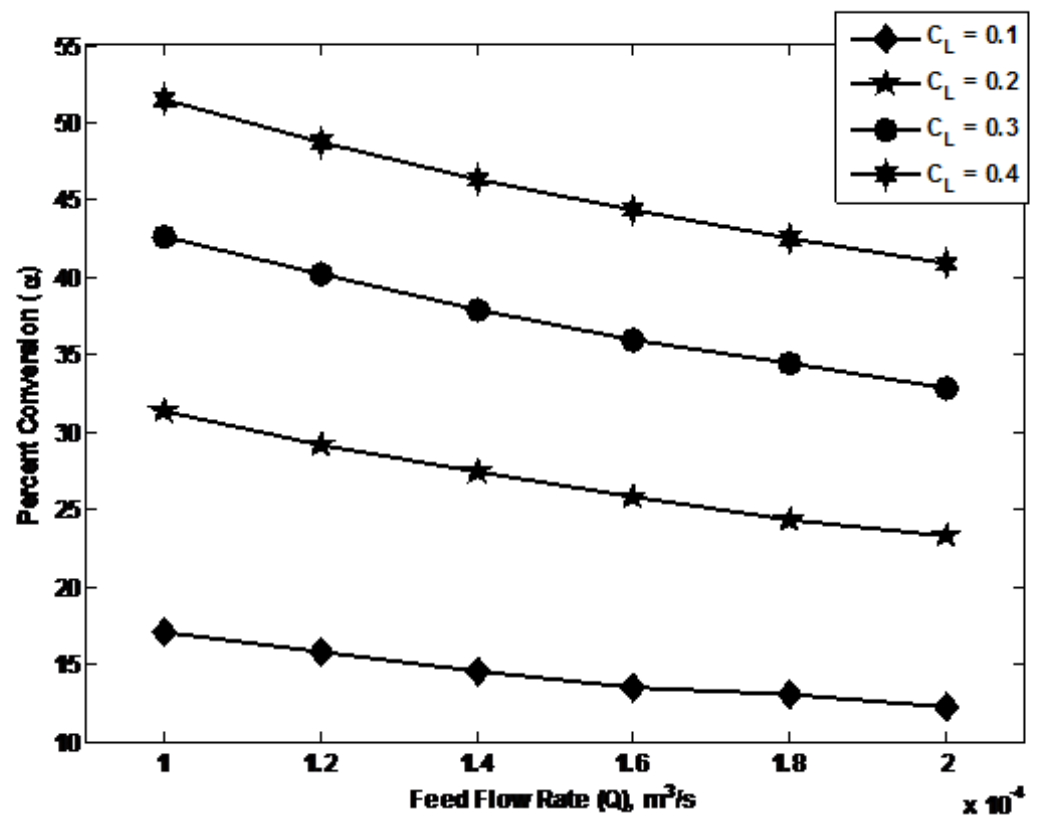

Fig 4: Variation of percent conversion with feed flow rate at different values of catalyst loading. $\mathrm{y}=1 / 7, \mathrm{~L}=\mathbf{6 . 0} \mathrm{m}, \mathrm{D}=\mathbf{2 5 . 4} \mathrm{mm}$, single flow channel

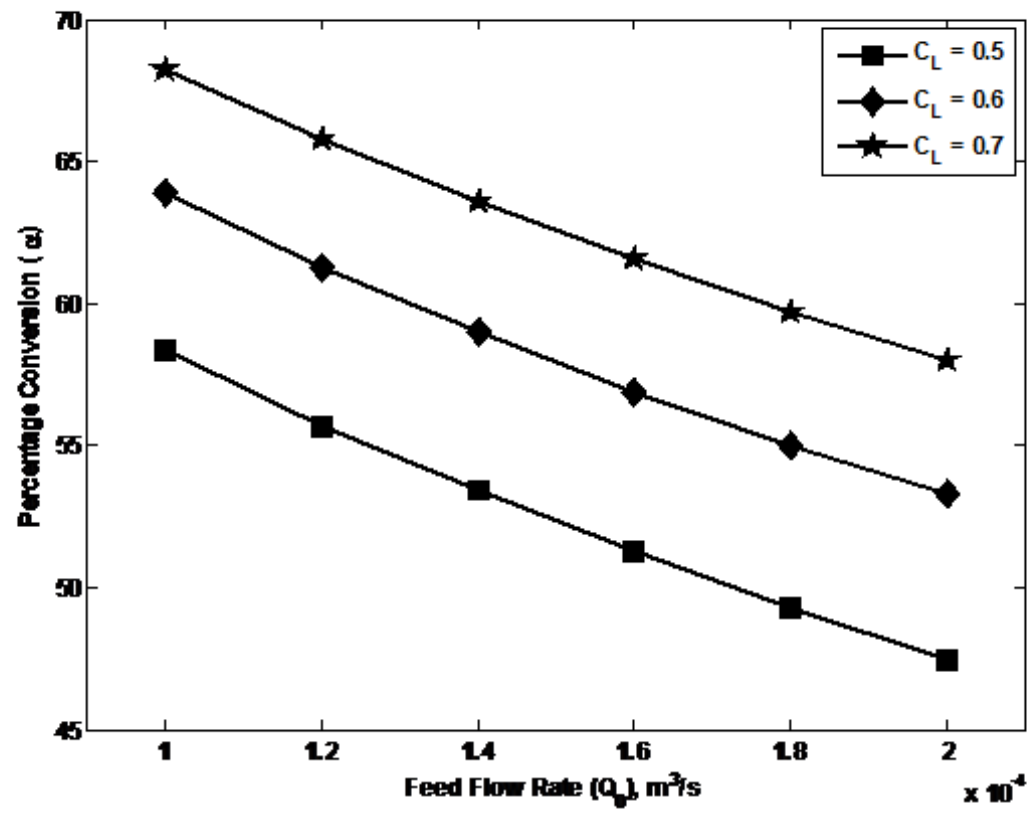

Fig 4a: Variation of percent conversion with feed flow rate at higher values of catalyst loading. $y=1 / 7, L=6.0 \mathrm{~m}, \mathrm{D}=\mathbf{2 5 . 4} \mathrm{mm}$, single flow channel 


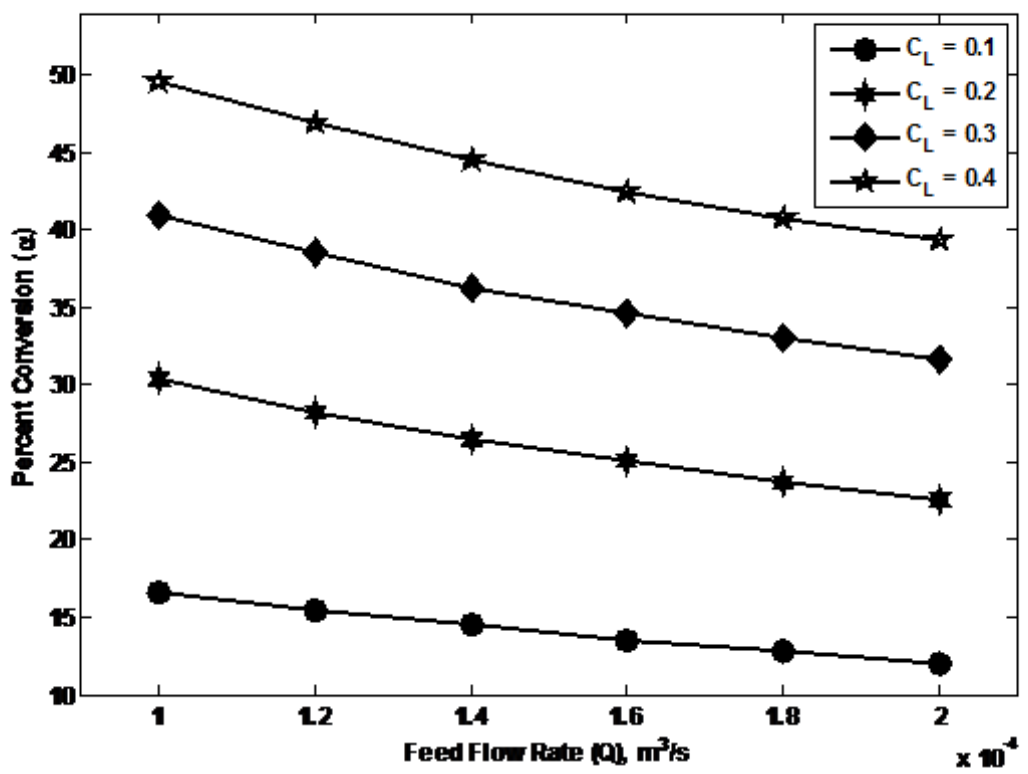

Fig 5: Variation of percent conversion with feed flow rate at different values of catalyst loading. $y=1 / 9, \mathrm{~L}=6.0 \mathrm{~m}, \mathrm{D}=\mathbf{2 5 . 4} \mathrm{mm}$, single flow channel

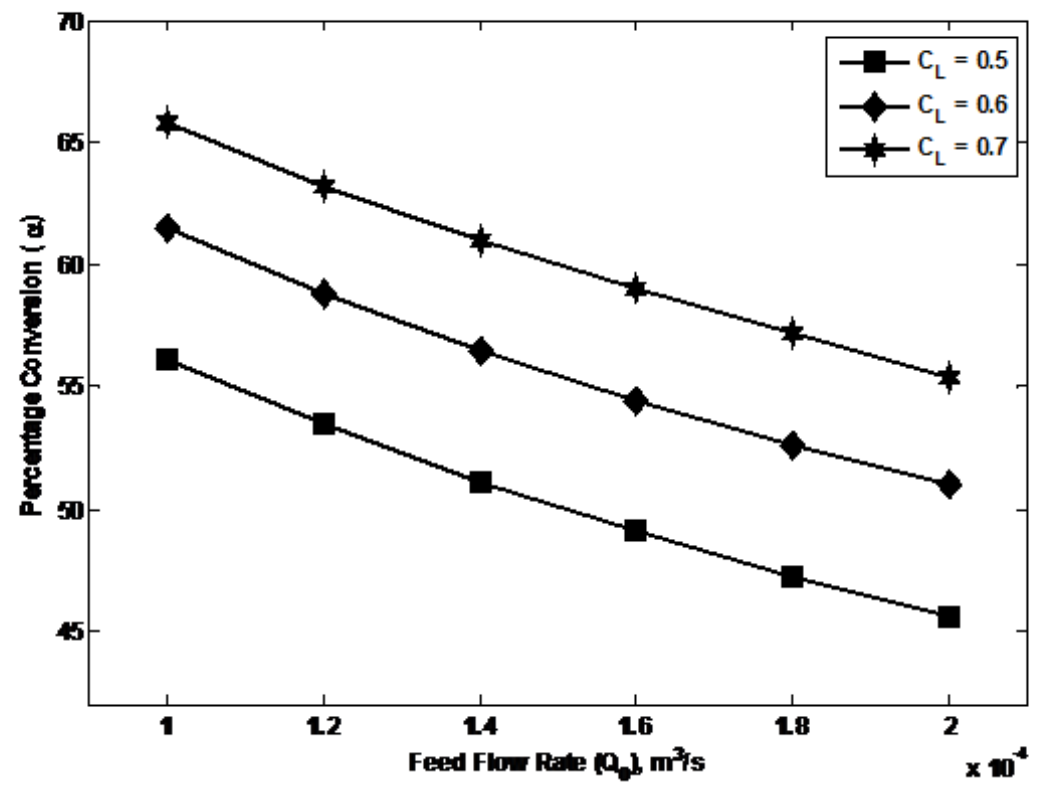

Fig 5a: Variation of percent conversion with feed flow rate at higher values of catalyst loading. $\mathrm{y}=1 / 9, \mathrm{~L}=6.0 \mathrm{~m}, \mathrm{D}=\mathbf{2 5 . 4} \mathrm{mm}$, single flow channel

The performance characteristics of the bioreactor have been fitted into analytical correlations by using Response Surface Methodology (RSM). The results are illustrated in figures (6a) to (6d). With reliable accuracy, the entire data presented in figures (2) to (5) could be fitted into an analytical correlation of the following form:

$$
\alpha=p_{00}+p_{10} Q_{0}+p_{01} C_{L}+p_{11} C_{L} Q_{0}+p_{02}\left(C_{L}\right)^{2}
$$

The values of correlation constants of above equation depend on the molar ratio of oil to acetate $(y)$ employed, as shown in tables (1) and (1A). 


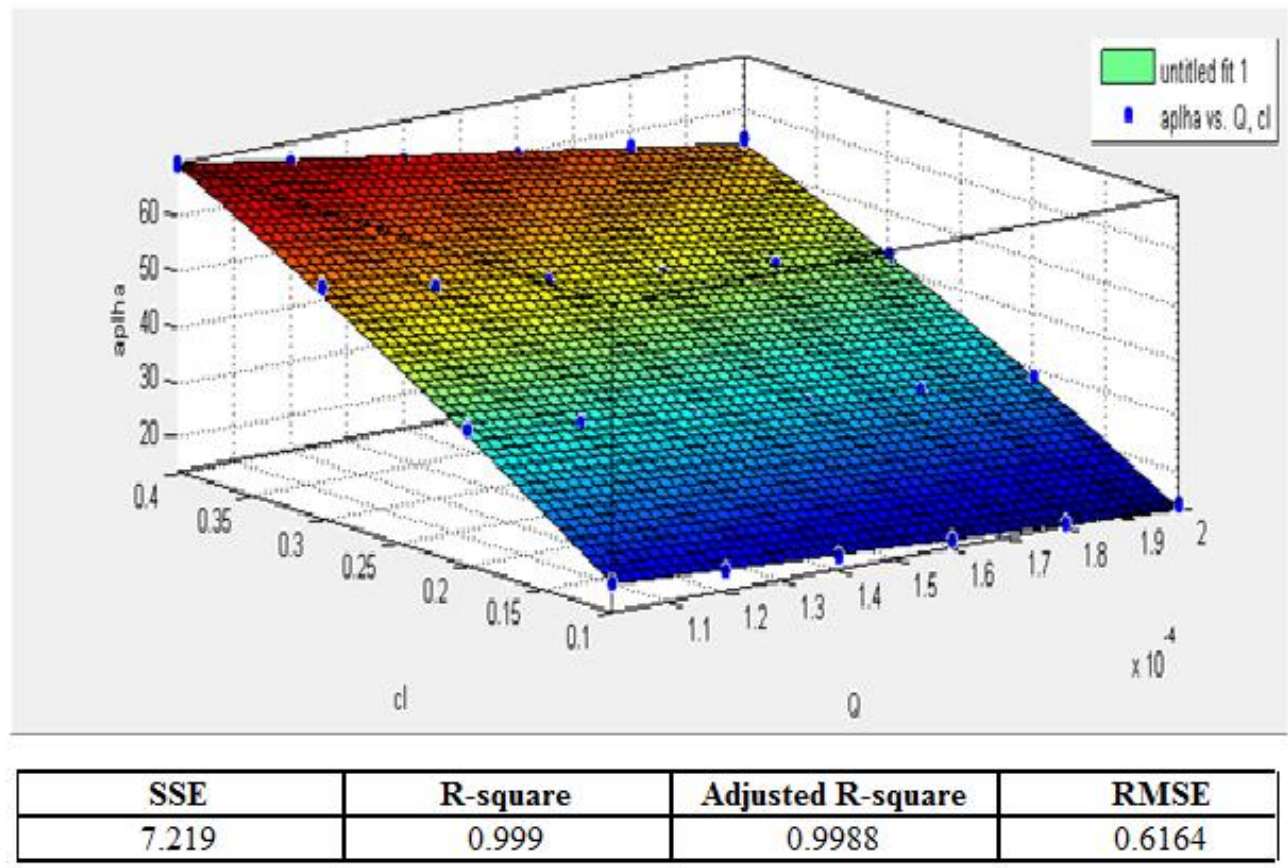

Fig. 6a : Sample RSM fit of fractional substrate conversion ( $\alpha$ ) against feed flow rate $\left(Q_{0}\right)$ and catalyst loading $\left(C_{L}\right)$. Molar ratio of oil to acetate, $y=1 / 3$.

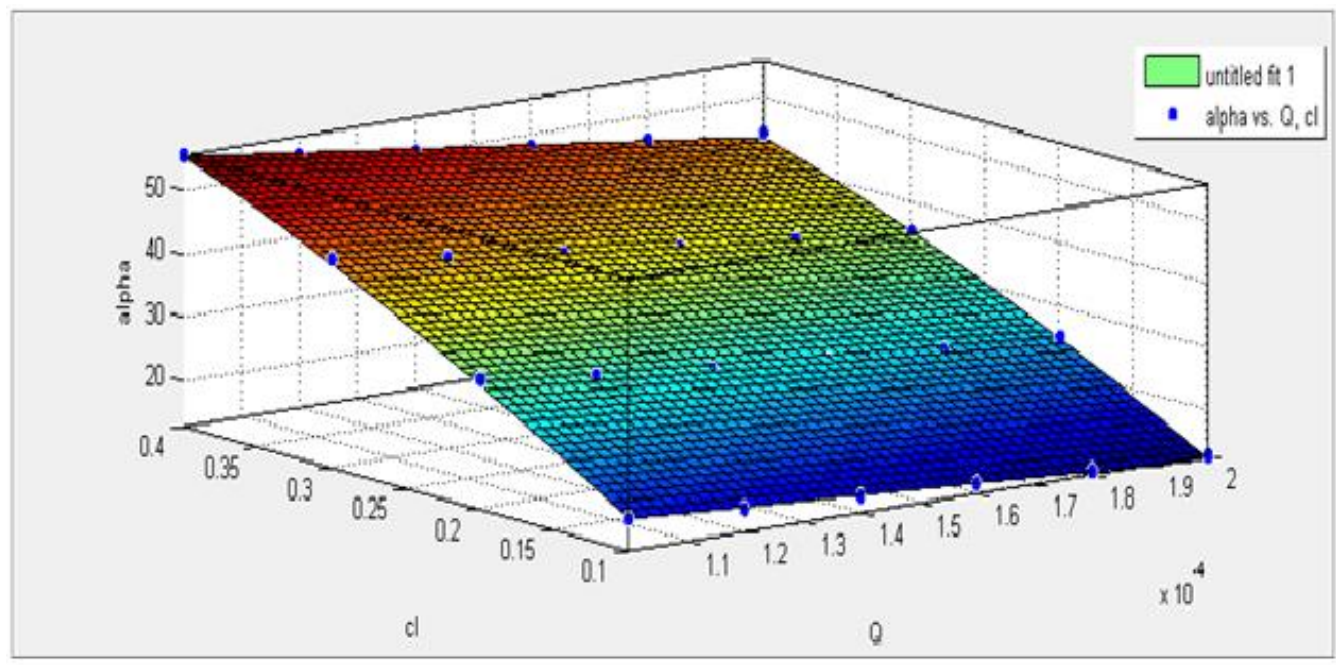

\begin{tabular}{|c|c|c|c|}
\hline SSE & R-square & Adjusted R-square & RMSE \\
\hline 4 & 0.999 & 0.9988 & 0.4589 \\
\hline
\end{tabular}

Fig. $6 \mathrm{~b}$ : Sample RSM fit of fractional substrate conversion ( $\alpha)$ against feed flow rate $\left(\mathrm{Q}_{0}\right)$ and catalyst loading $\left(C_{L}\right)$. Molar ratio of oil to acetate, $y=1 / 5$. 


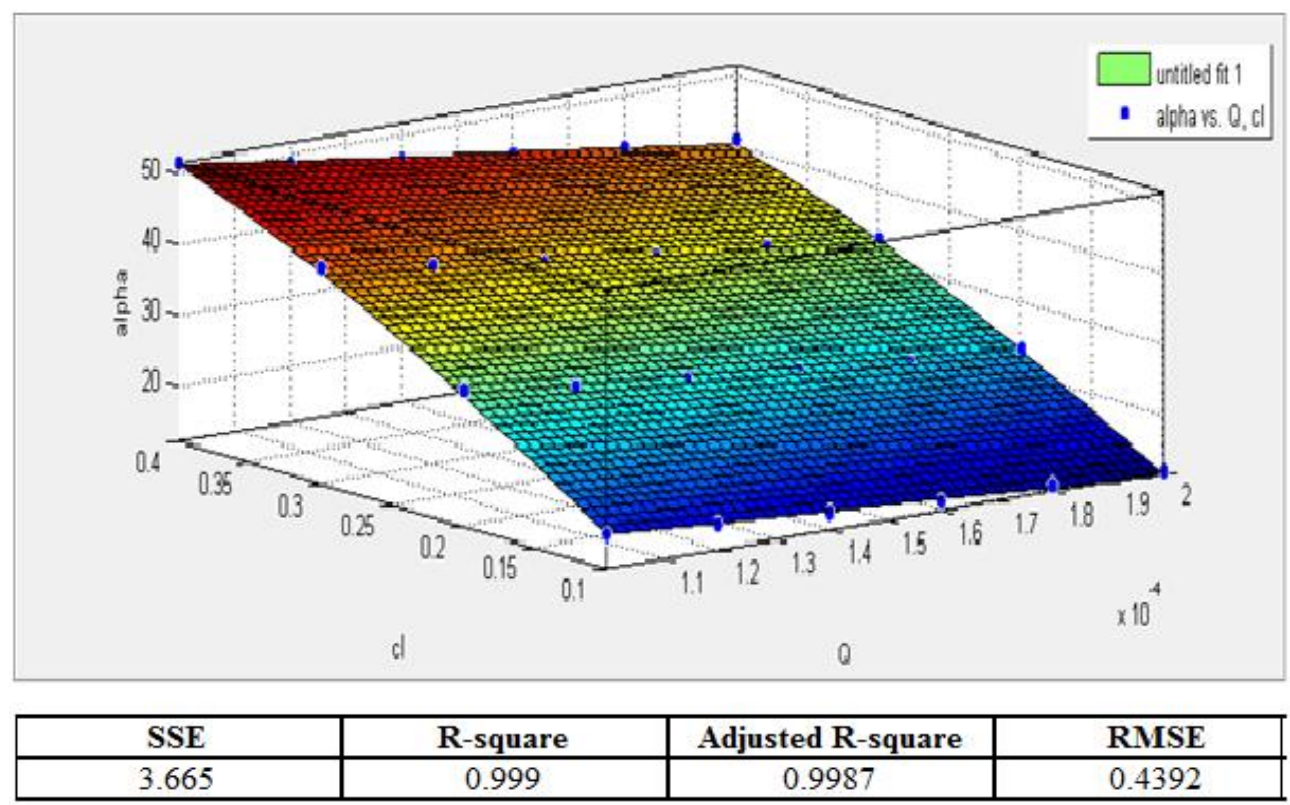

Fig. 6c : Sample RSM fit of fractional substrate conversion ( $\alpha$ ) against feed flow rate $\left(Q_{0}\right)$ and catalyst loading $\left(C_{L}\right)$. Molar ratio of oil to acetate, $y=1 / 7$.

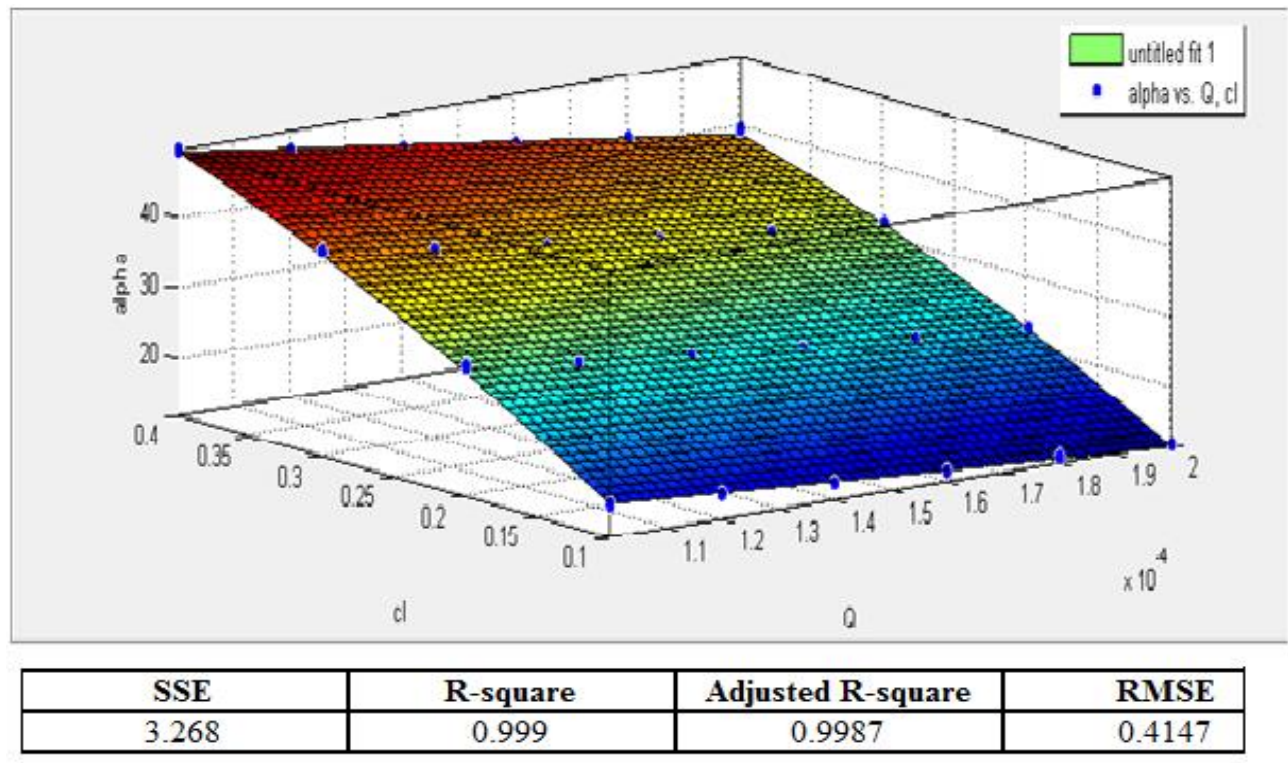

Fig. 6d : Sample RSM fit of fractional substrate conversion ( $\alpha$ ) against feed flow rate $\left(Q_{0}\right)$ and catalyst loading $\left(C_{L}\right)$. Molar ratio of oil to acetate, $y=1 / 9$.

Table : 1 Coefficients of Equation (31), $C_{L}=0.1$ to 0.4

\begin{tabular}{|l|l|l|l|l|l|}
\hline $\mathbf{y}$ & $p_{00}$ & $p_{10}$ & $p_{01}$ & $p_{11}$ & $p_{02}$ \\
\hline $\mathbf{1 / 3}$ & 1.507 & $-2.707 \times 10^{4}$ & 240.7 & $-3.241 \times 10^{5}$ & -82.92 \\
\hline $\mathbf{1 / 5}$ & 5.103 & $-3.596 \times 10^{4}$ & 195.7 & $-2.082 \times 10^{5}$ & -100.5 \\
\hline $\mathbf{1 / 7}$ & 5.265 & $-3.657 \times 10^{4}$ & 184.1 & $-1.856 \times 10^{5}$ & -103.8 \\
\hline $\mathbf{1 / 9}$ & 5.328 & $-3.304 \times 10^{4}$ & 175.6 & $-1.862 \times 10^{5}$ & -97.29 \\
\hline
\end{tabular}


Table : $1 \mathrm{~A}$ Coefficients of Equation (31), $\mathrm{C}_{\mathrm{L}}=0.5$ to 0.7

\begin{tabular}{|l|l|l|l|l|l|}
\hline $\mathbf{y}$ & $p_{00}$ & $p_{10}$ & $p_{01}$ & $p_{11}$ & $p_{02}$ \\
\hline $\mathbf{1 / 3}$ & 37.96 & $2.56 \times 10^{5}$ & 166.2 & $2.403 \times 10^{5}$ & -117 \\
\hline $\mathbf{1 / 5}$ & 30.03 & $-1.436 \times 10^{5}$ & 118.7 & $5.929 \times 10^{4}$ & -60.83 \\
\hline $\mathbf{1 / 7}$ & 27.54 & $-1.245 \times 10^{5}$ & 108.7 & $3.214 \times 10^{4}$ & -52 \\
\hline $\mathbf{1 / 9}$ & 26.66 & $-1.244 \times 10^{5}$ & 105 & $3.143 \times 10^{4}$ & -50 \\
\hline
\end{tabular}

\section{CONCLUSIONS}

a) Biodiesel synthesis by trans-esterification of neem oil with methyl acetate and catalysed by lipase enzyme immobilized in nanosilica particles has been studied and simulated both mathematically as well as experimentally (pilot plant tests) in inverse fluidised bed bioreactor of modified design.

b) The bioreactor provides more than $80 \%$ conversion of neem oil at a catalyst loading of 0.6 and above, when molar ratio of oil to acetate in the blend is maintained at 0.33 (stoichiometric proportion) at feed flow rates of 700 to $720 \mathrm{~L} / \mathrm{h}$ (with a single column of ID $25.4 \mathrm{~mm}$ and height $6.0 \mathrm{~m}$ ). By using a multiple tube/column, construction consisting of 5-6 tubes/ columns, the capacity of the reactor can be increased to 3600 to $4500 \mathrm{~L} / \mathrm{h}$.

c) Catalyst loading more than 0.7 is wasteful since $\alpha$ (attained) is significantly high at $C_{L}=0.6$ to 0.7 .

d) High excess of methyl acetate (more than the stoichiometric requirement of $y=1: 3$ ) is undesirable as it tends to bring down the degree of trans-esterification attained. Methyl acetate causes substrate inhibition to enzyme activity at high concentrations.

e) One of the unique features of the bioreactor of proposed design is that due to the enormously large specific surface of nanosilica particles, the effectiveness factor $(\eta)$ is equal to 1.0 and consequently, the global rate of transesterification attained is quite high as it is equal to the intrinsic rate itself. This thus enhances the performance of the bioreactor.

f) The performance features of bioreactor and the process characteristics of biodiesel synthesis have been fitted into analytical correlations using RSM (Response Surface Methodology). These correlations are quite compact and thereby help in locating the optimum combination of process/ system parameters for any specific application.

g) Due to the downflow mode of operation, the operating cost of the bioreactor shall be substantially low. The cost of operation of the pneumatic column shall also be quite low. The major share of the operating cost shall be that of the nano-membrane filter employed to separate the nanosilica particles.

\section{ACKNOWLEDGEMNTS}

The authors are deeply indebted to all members of their research group, who worked hard with them during the development of the software package. Special vote of thanks to two consultancy firms of Bangalore, India and New Jersey, USA for their assistances during the experimental investigation.

\section{NOMENCLATURE}

$C_{B D}$ molar concentration of methyl acetate in the feed solution, $\mathrm{mol} / \mathrm{L}$

$C_{L}$ catalyst loading, $\mathrm{kg} / \mathrm{kg}$

$C_{S B}$ molar concentration of methyl acetate at any $\mathrm{z}, \mathrm{mol} / \mathrm{L}$

$C_{S}$ concentration of neem oil at any $\mathrm{z}, \mathrm{mol} / \mathrm{L}$

$C_{S E}$ concentration of neem oil in the product solution, $\mathrm{mol} / \mathrm{L}$

$C_{\text {SU }}$ concentration of neem oil in the feed solution, $\mathrm{mol} / \mathrm{L}$

D diameter of reactor column, $\mathrm{m}$

$D_{L}$ axial dispersion coefficient, $\mathrm{m}^{2} / \mathrm{s}$

$K_{\text {S1 }}, K_{\text {S2 }}$ kinetic constants, mole/L

$K_{S i}$ substrate inhibition coefficient, mole/L

$\mathrm{L}$ height of reactor column, $\mathrm{m}$

$\mathbf{6 0 8 4} \mid \mathrm{P}$ a g e

February 2018 
$M_{A}$ molecular weight of neem oil, $\mathrm{kg} / \mathrm{kmol}$

$M_{B}$ molecular weight of methyl acetate, $\mathrm{kg} / \mathrm{kmol}$

$Q_{0}$ volumetric flow rate of substrate solution, $\mathrm{m}^{3} / \mathrm{s}$

$r_{\max }$ kinetic constant, $\mathrm{mol} /(\mathrm{g} . \mathrm{sec})$

$\left(-r_{S}\right)$ (int) intrinsic rate of trans-esterification reaction, $\mathrm{mol} /($ L.s $)$

$U$ (sup) superficial velocity of substrate solution through the reactor column, $\mathrm{m} / \mathrm{s}$

$U_{L}$ average velocity of feed slurry/suspension through the bioreactor column, $\mathrm{m} / \mathrm{s}$

$x_{A}$ mass fraction of neem oil in the substrate solution

y molar ratio of neem oil to methyl acetate in the blend(feed solution), dimensionless

z axial coordinate

$\varepsilon_{\mathrm{L}}$ volume fraction of liquid in the feed slurry/suspension, dimensionless

$\eta$ effectiveness factor, dimensionless

$\rho_{A}, \rho_{B}$ density of neem oil and that of methyl acetate respectively, $\mathrm{kg} / \mathrm{m}^{3}$

$\rho_{s}$ density of nanosilica particles, $\mathrm{kg} / \mathrm{m}^{3}$

$\rho_{L}$ density of substrate solution(oil-acetate blend), $\mathrm{kg} / \mathrm{m}^{3}$

$\rho_{\text {Lm }}$ bulk density of feed slurry/suspension, $\mathrm{kg} / \mathrm{m}^{3}$

$\mu_{L} \quad$ viscosity of substrate solution, $\mathrm{kg} /(\mathrm{m} . \mathrm{s})$

$\gamma_{A^{x}} \gamma_{B}$ kinematic viscosity of neem oil and that of methyl acetate respectively, centistokes

$\alpha$ fractional conversion of neem oil, dimensionless

\section{REFERENCES}

1. Dossat, V., Combes, D., Marty, A..2002. Lipase-catalysed transesterification of high oleic sunflower oil. Enzyme Microb. Tech.30, 90-95.

2. Du, W., Xu, Y.Y, Liu, D.H. 2005. Study on Kinetics of Enzymatic Interesterification of Triglycerides for Biodiesel Production with Methyl Acetate as Acyl Acceptor., J. Mole. Catalysis. 32, 241-47.

3. Jegannathan, K.R., Abang,S., Poncelet, D., Chan, E.S., Ravindra, P. 2008. Production of Biodiesel Using Immobilized Lipase - A Critical Review. Critical Rev..Biotech. 21,253-58.

4. Khan, S.A., Hussain, M.Z., Prasad, S., Banerjee, U.C.2009. Prospects of biodiesel production from microalgae in India. Renewable Sustainable Energy Rev.13, 2361-67.

5. Narayanan, C.M., De, T. 2014. Studies on Synthesis of Biodiesel from Microalgae Oil in Immobilized Lipase Fluidised Bed Bioreactor. Biomass Conv. Bioref. 5, 33-38.

6. Halim, S.F.A., Kamaruddin, A.H. 2008.Continuous Bio-Synthesis of Biodiesel from Waste Cooking Palm Oil in Packed Bed Reactor, Process Biochem. 43,1436-40.

7. Sucharitha, G., Kumaraswamy, A. 2013.Experimental Analysis of Biodiesel Synthesis Using Neem Oil as an Alternative Fuel. Int. J. Eng. Res.Appli. 3,320-25.

8. De, T., Sikder, J., Narayanan, C.M. 2015. Studies on Synthesis of Biodiesel by Trans-esterification of Neem Oil with Immobilized Lipase in Cylindrical and Diverging-Converging Fluidized Bed Bioreactors. Int. J. Chem. Env. Eng. 6,( 5), 322-27.

9. Du, W, Xu, Y.Y., Liu, D.H., Zeng, J. 2004. Comparative Study on Lipase-Catalyzed Transformation of Soybean Oil for Biodiesel Production with Different Acyl Acceptors. J. Mole. Catalysis B. Enzym. 30,125-30.

10. Feyzi M., Norouzi L.2016. Preparation and kinetic study of magnetic $\mathrm{Ca} / \mathrm{Fe}_{3} \mathrm{O}_{4} @ \mathrm{SiO}_{2}$ nanocatalysts for biodiesel production. Renewable Energy, 94, 579-85.

11. Hu S., Wen L., Wang Y., Zheng X., Han H. 2012. Gas-liquid countercurrent integration process for continuous biodiesel production using a microporous solid base $\mathrm{KF} / \mathrm{CaO}$ as catalyst. Bioreso. Tech. 123, 413-17.

12. Kawashima A., Matsubara K., Honda K. 2008. Development of heterogeneous base catalysts for biodiesel production. Bioreso. Tech. 99, 3439-43.

$\mathbf{6 0 8 5} \mid \mathrm{P}$ a g e

February 2018 
13. Long Y-D., Fang Z., Su T-C, Yang Q. 2014. Co-production of biodiesel and hydrogen from rapeseed and Jatropha oils with sodium silicate and Ni catalysts. Applied Energy. 113,1819-23.

14. Narayanan, C.M. 2011.Studies on Performance Characteristics of Circulating Fluidized Bed Bioreactors employing Immobilized Enzyme Nanoparticles. IUP J. Chem. Eng. 3(4),17-24.

15. Narayanan, C.M., Tejaswi, M., Prasad, H., Chakraborty,N. 2014. Studies on Performance Analysis and Computer Aided Design of Inverse Fluidized Bed Bioreactors with Nano -support Particles. Int. J.Chem. Reactor Eng 12(1),303-309.

16. Ulaganathan, N., Krishnaiah, K. 1996. Hydrodynamic Characteristics of Two Phase Inverse Fluidized Bed. Bioproc. Eng. 15,159-63.

17. Narayanan, C.M., Das, S.2016.Computer Aided Design and Performance Analysis of Inverse Fluidized Bed Biofilm Reactors With Special Reference to Bioplastic Synthesis. Adv. Chem. Eng.Sci. 6, 130-36.

18. Levenspiel, O.1958.Axial Dispersion in Tubular Flow. Ind. Eng. Chem. 50, 343-46.

19. De, T. 2017.Studies on Synthesis of Biodiesel in Enzyme Fluidized Bed Bioreactors. PhD Thesis, National Institute of Technology, Durgapur, India.

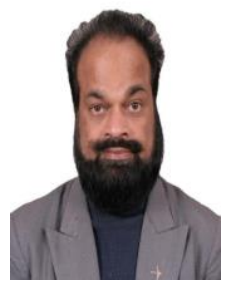

Prof. (Dr.) C.M Narayanan has been Professor of Chemical Engineering at National Institute of Technology, Durgapur, India, during 1977 to 2016. After 39 ( thirty nine) years of service, he retired from NIT in 2016 and is presently a freelance Software Consultant and Guest Faculty to three Engineering Institutions. He is the author of 105 (one hundred and five) research papers in Journals of international repute. $\mathrm{He}$ is also the author of six well known books on Chemical Engineering and Biotechnology including a Chapter (Chapter-1, Volume 2 ) of the Handbook of Food Bioengineering published by Elsevier in 20 (twenty) Volumes. He is a member of Review Board / editorial board of many International Journals and has established five SSI units. He has been conferred with many awards such as the BHARAT JYOTI award, the MOST EMINENT ENGINEERING PERSONALITY Award, the most distinguished alumnus award. Visit him at : www.profcmn.com

Ms. Aditi Pandey completed her B.Tech in Chemical Engineering from National Institute of Technology, Durgapur, India in 2016. After serving as a graduate engineer in one of the leading power plants of India for one year, she is presently pursuing her MBA at Indian Institute of Management, Kozhikode, India. She has co-authored two research papers with Prof. Narayanan and has also co-authored Chapter 1, Volume 2 of Handbook of Food Bioengineering. 